\title{
Effect of intravenous anesthetic propofol on synaptic vesicle exocytosis at the frog neuromuscular junction
}

\author{
Luciana Ferreira LEITE ${ }^{1}$, Renato Santiago GOMEZ $^{2, *}$, Matheus de Castro FONSECA ${ }^{1}$, Marcus Vinicius GOMEZ ${ }^{3}$, Cristina \\ GUATIMOSIM ${ }^{1, \S}$
}

\begin{abstract}
${ }^{1}$ Department of Morphology, Federal University of Minas Gerais, Belo Horizonte, Minas Gerais, Brazil; ${ }^{2}$ Department of Surgery, School of Medicine, Federal University of Minas Gerais, Belo Horizonte, Minas Gerais, Brazil; ${ }^{3}$ Graduate Program of Santa Casa, Belo Hori-

zonte, Minas Gerais, Brazil
\end{abstract}

\begin{abstract}
Aim: To investigate the presynaptic effects of propofol, a short-acting intravenous anesthetic, in the frog neuromuscular junction. Methods: Frog cutaneous pectoris nerve muscle preparations were prepared. A fluorescent tool (FM1-43) was used to visualize the effect of propofol on synaptic vesicle exocytosos in the frog neuromuscular junction.

Results: Low concentrations of propofol, ranging from 10 to $25 \mu \mathrm{mol} / \mathrm{L}$, enhanced spontaneous vesicle exocytosis monitored by FM143 in a $\mathrm{Ca}^{2+}$-dependent and $\mathrm{Na}^{+}$-independent fashion. Higher concentrations of propofol (50, 100, and $\left.200 \mu \mathrm{mol} / \mathrm{L}\right)$ had no effect on spontaneous exocytosis. By contrast, higher concentrations of propofol inhibited the $\mathrm{Na}^{+}$-dependent exocytosis evoked by 4-aminopyridine but did not affect the $\mathrm{Na}^{+}$-independent exocytosis evoked by $\mathrm{KCl}$. This action was similar and non-additive with that observed by tetrodotoxin, a $\mathrm{Na}^{+}$channel blocker.

Conclusion: Our data suggest that propofol has a dose-dependent presynaptic effect at the neuromuscular transmission which may help to understand some of the clinical effects of this agent on neuromuscular function.
\end{abstract}

Keywords: propofol; neuromuscular junction; frog; FM1-43; synaptic vesicle; general anesthetic

Acta Pharmacologica Sinica (2011) 32: 31-37; doi: 10.1038/aps.2010.175; published online 29 Nov 2010

\section{Introduction}

During the last decade, there was a significant progress related to the knowledge of the mechanism of action of general anesthetic. Cellular and molecular mechanisms underlying general anesthesia are not yet fully elucidated but general anesthetics seems to act in both presynaptic and postsynaptic molecular targets $^{[1-4]}$. There is now a great body of evidences that clinical concentrations of most general anesthetics act on specific ligand-gated ion channels like GABA and glutamate receptors and/or other important ion channels, such as voltage gated sodium channels, potassium channels and HCN-pacemaker channels ${ }^{[3]}$. Nevertheless, characterizing the molecular targets of general anesthetics has challenged many research groups over the years.

Propofol is one of the most widely used general anesthetic

\footnotetext{
$\S$ Now in Center for Brain Sciences and Department of Molecular and Cellular Biology, Harvard University, 52 Oxford Street, Cambridge, MA 02138, USA.

* To whom correspondence should be addressed.

E-mail renatogomez2000@yahoo.com.br

Received 2010-07-13 Accepted 2010-09-14
}

agent for induction and maintenance of anesthesia. Previous works performed in central nervous system (CNS) synapses have shown an inhibition of calcium channels by propofol ${ }^{[5-7]}$. Other works showed that propofol inhibited calcium-dependent glutamate release evoked by veratridine and 4-AP with greater potency than $\mathrm{Na}^{+}$channel-independent release evoked by $\mathrm{KCl}^{[8,9]}$. In addition, there were evidences in the literature suggesting that high doses of propofol might have a direct effect on $\mathrm{Na}^{+}$channels ${ }^{[9-13]}$.

It is well described the sedative and hypnotic effects of propofol on CNS. Nevertheless, there are few studies investigating its effect on neuromuscular transmission. Indeed, it has been proposed that propofol has a dual effect on the neuromuscular junction. Low concentrations of propofol stimulate skeletal muscle contractions elicited direct and indirectly ${ }^{[14]}$ but high concentrations of this agent inhibit skeletal muscle contractions evoked direct and indirectly ${ }^{[15,16]}$. The mechanisms underlying the neuromuscular effects of propofol include reduction of muscular blood flow, a direct effect on the post-junctional membrane receptors, and reduction on acetylcholine $(\mathrm{ACh})$ release on the neuromuscular junction ${ }^{[17-23]}$. 
FM1-43 is a fluorescent tool that has been used to study synaptic vesicle recycling at the neuromuscular junction ${ }^{[24-26]}$. The molecular characteristics of this fluorescent marker allow its internalization during synaptic vesicle endocytosis as well as its release during exocytosis ${ }^{[25]}$. In the present work, we investigated the effect of propofol on synaptic vesicle exocytosis, a crucial step for neurotransmitter release. We used FM143 to visualize the effect of several concentrations of propofol on spontaneous and evoked exocytosis at frog neuromuscular junction.

\section{Materials and methods Reagents}

FM1-43 was purchased from Molecular Probes (Eugene, OR, $\mathrm{USA}), d$-tubocurarine, 4-aminopyridine (4AP), tetrodotoxin (TTX), 2APB, dantrolene and omega-conotoxin GVIA were purchased from Sigma-Aldrich (St Louis, MO, USA). Propofol was obtained from Fresenius (Uppsala, Sweden) and azumolene was obtained from Proctor \& Gamble (Norwich, NY, USA). All other chemicals and reagents were of analytical grade. All procedures were approved by the local animal care committee (CETEA-UFMG).

\section{Staining and destaining with FM1-43}

The frog neuromuscular junction has been an invaluable experimental model for elucidating many aspects of neurotransmission which is the basis of neuronal communication. Two decades ago, Betz and colleagues have introduced the use of the fluorescent dye FM1-43 to visualize synaptic vesicles recycling in motor nerve terminals of the frog neuromuscular junction ${ }^{[24,25,27]}$. Using this powerful tool, it was possible to elucidate the mechanisms that governed synaptic vesicle recycling and consequently neurotransmitter release in several neuronal cell types ${ }^{[28]}$.

In the present work, frog cutaneous pectoris nerve muscle preparations were dissected from Rana catesbeiana (about $60 \mathrm{~g}$ ) and mounted in a sylgard-lined chamber containing frog Ringer solution $(115 \mathrm{mmol} / \mathrm{L} \mathrm{NaCl}, 2.5 \mathrm{mmol} / \mathrm{L} \mathrm{KCl}$, $1.8 \mathrm{mmol} / \mathrm{L} \mathrm{CaCl}_{2}, 5 \mathrm{mmol} / \mathrm{L}$ HEPES, $\mathrm{pH}$ 7.2). FM1-43 (4 $\mu \mathrm{mol} / \mathrm{L})$ was used to stain the recycling pool of synaptic vesicles ${ }^{[25]}$. This dye presents a hydrophobic tail that reversibly binds to membranes and a polar head that impairs it to fully permeate the plasma membrane ${ }^{[24-28]}$. Therefore, FM143 binds to synaptic membrane and when the nerve terminal is submitted to a stimulus that causes exocytosis of synaptic vesicles and, consequently, a compensatory endocytosis, the fluorescent dye is incorporated, resulting in a typical pattern of staining ${ }^{[25]}$. After a new round of stimulation, in the absence of FM1-43 in the external medium, the dye is released to the hydrophilic medium, resulting in a decrease of fluorescence intensity, reflecting the exocytosis of synaptic vesicle ${ }^{[24-26]}$. In our experiments, the muscles were incubated with $d$-tubocurarine $(16 \mu \mathrm{mol} / \mathrm{L})$ to prevent contractions during stimulation. The muscles were stimulated for $10 \mathrm{~min}$ with modified Ringer solution $(57.5 \mathrm{mmol} / \mathrm{L} \mathrm{NaCl}, 60 \mathrm{mmol} / \mathrm{L} \mathrm{KCl}, 1.8 \mathrm{mmol} / \mathrm{L}$ $\mathrm{CaCl}_{2}, 5 \mathrm{mmol} / \mathrm{L}$ HEPES, $\mathrm{pH}$ 7.2) in the presence of FM1-43
$(4 \mu \mathrm{mol} / \mathrm{L})$. Thereafter, the preparation was kept resting for 15 min to guarantee FM1-43 uptake. The excess of FM1-43 adhered to the muscle membranes was removed during an one hour washing period in frog Ringer solution. Images were acquired in intervals of $5 \mathrm{~min}$ until the end of the experiments. The destaining at the absence of stimulus (photobleaching) was used as a control.

After labeling with FM1-43, neuromuscular preparations were exposed to different concentrations of propofol during $30 \mathrm{~min}$ to evaluate its effect on spontaneous exocytosis. Experiments were also performed to investigate the effect of propofol on $\mathrm{Na}^{+}$-dependent exocytosis evoked by 4AP. After labeling neuromuscular preparations with FM1-43, muscles were exposed to $4 \mathrm{AP}(1 \mathrm{mmol} / \mathrm{L})$ during $30 \mathrm{~min}$. To test the role of extracellular $\mathrm{Na}^{+}$on $4 \mathrm{AP}$-evoked exocytosis, the neuromuscular preparation was initially incubated for $30 \mathrm{~min}$ in frog Ringer containing $1.0 \mu \mathrm{mol} / \mathrm{L} \mathrm{TTX}$ and, thereafter, it was exposed to $4 \mathrm{AP}$ for $30 \mathrm{~min}$. The propofol effect on 4AP-induced exocytosis was investigated by pre-incubation in propofol $(100 \mu \mathrm{mol} / \mathrm{L})$ solution during $10 \mathrm{~min}$ before $4 \mathrm{AP}$ exposure. Similar protocols were applied to investigate the effects of propofol and TTX on $\mathrm{Na}^{+}$-independent exocytosis evoked by $60 \mathrm{mmol} / \mathrm{L} \mathrm{KCl}$.

Experiments that investigated the role of extracellular $\mathrm{Ca}^{2+}$ on the vesicular release induced by propofol were performed in modified Ringer solution without $\mathrm{Ca}^{2+}$ but containing EGTA $(2.0 \mathrm{mmol} / \mathrm{L})$, an extracellular $\mathrm{Ca}^{2+}$ chelator. The preparations were incubated in modified Ringer during $30 \mathrm{~min}$ before application of propofol. In experiments performed with the calcium channel blocker omega-conotoxin GVIA, the preparations were pre-incubated in Ringer containing toxin for $30 \mathrm{~min}$ before propofol. The participation of intracellular $\mathrm{Ca}^{2+}$ stores on the exocytosis evoked by propofol was also investigated. For this purpose, preparations were incubated for $30 \mathrm{~min}$ in Ringer containing $2 \mathrm{APB}(100 \mu \mathrm{mol} / \mathrm{L})$, an $\mathrm{IP}_{3}$ receptor blocker, or azumolene $(100 \mu \mathrm{mol} / \mathrm{L})$, a ryanodine receptors blocker before the addition of propofol.

\section{Fluorescence microscopy and imaging analyses}

Images were acquired using a fluorescence microscope (Zeiss Axioskop) coupled to a CCD camera (Micromax) and visualized in a computer. The microscope was equipped with water immersion objectives $(63 \times, 0.95 \mathrm{NA}$ and $40 \times, 0.75 \mathrm{NA})$. Excitation light came from a $100 \mathrm{~W} \mathrm{Hg}$ lamp and passed through filters $(505 / 530 \mathrm{~nm})$ to select the fluorescence spectrum. The experimental parameters for collection of images were always identical in control and test contralateral muscles in a given trial.

\section{Statistical analysis}

Image analysis was performed using the softwares Image J and Microsoft Excel. The mean fluorescence intensity was determined for each group of spots and plotted against the time as percentage of its mean initial fluorescence using the software Sigma Plot 9.0. Statistical analysis was performed using paired Student's $t$-Test or ANOVA. $P<0.05$ values were 
considered statistically significant.

\section{Results}

\section{FM1-43 staining and destaining of nerve terminals}

Frog cutaneous-pectoris neuromuscular junctions were stained with FM1-43 as previously described ${ }^{[25]}$. The nerve terminal that was stained with FM1-43 shows fluorescent spots corresponding to clusters of synaptic vesicles that were able to pick up the dye (Figure 1A, upper panel). When this previously labeled terminal was submitted to a new depolarizing stimulus by modified Ringer containing $60 \mathrm{mmol} / \mathrm{L} \mathrm{KCl}$, in the absence of FM1-43 in external medium, we observed a significant reduction in fluorescence (Figure 1A, lower panel). The loss of fluorescence was due to dye release to external medium, that correspond to synaptic vesicle exocytosis ${ }^{[25]}$. Exposure of nerve terminals to illumination without any depolarizing stimulus resulted in a small decrease on fluorescence (maximum 10\%) attributable to dye photobleaching ${ }^{[28]}$. A representative image of the terminal before (upper panel) and after illumination (lower panel), in the absence of stimulus, is shown in Figure 1B. To quantify the decrease in fluorescence that occurs after stimulation with $60 \mathrm{mmol} / \mathrm{L} \mathrm{KCl}$ and photobleaching, the mean fluorescence intensity for each synaptic vesicle cluster was measured and plotted as gray levels against time (Figure $1 \mathrm{C}$ ). The small reduction in fluorescence observed corresponds to photobleaching whereas the larger destaining curve obtained during depolarization stimulus corresponds to synaptic vesicle exocytosis.
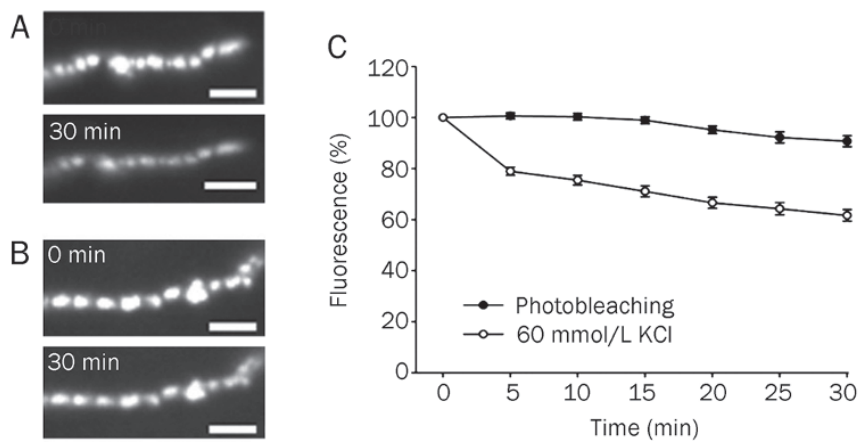

Figure 1. Synaptic vesicles recycling visualized by the fluorescent dye FM1-43. (A) Upper panel: Representative nerve terminal that was incubated in modified Ringer containing $60 \mathrm{mmol} / \mathrm{L} \mathrm{KCl}$ for 10 min in the presence of FM1-43. Note the formation of fluorescent spots, corresponding to clusters of synaptic vesicles that were able to pick up dye. Lower panel: The same terminal after a second round of depolarization with modified Ringer containing $60 \mathrm{mmol} / \mathrm{L} \mathrm{KCl}$, now in the absence of extracellular dye. Note a pronounced destaining of fluorescent spots, corresponding to exocytosis of synaptic vesicles and dye release to the external medium. (B) Representative image of fluorescence loss due to photobleaching during illumination for $30 \mathrm{~min}$. Upper panel: before illumination. Lower panel: after 30 min of illumination. (C) Quantification of FM1-43 fluorescence loss due to photobleaching and $\mathrm{KCl}$ fluorescence loss due to exocytosis of synaptic vesicles. The results are mean \pm SEM of 65 spots from 8 nerve terminals of 4 animals. Scale Bar $=10 \mu \mathrm{m}$.
Effect of low concentrations of propofol on spontaneous synaptic vesicle exocytosis

Nerve terminals labeled with FM1-43 were bathed in different concentrations of propofol (10 to $200 \mu \mathrm{mol} / \mathrm{L}$ ) for $30 \mathrm{~min}$ (Figure 2). Fluorescence of representative terminals before and after photobleaching (Figure 2A); propofol $10 \mu \mathrm{mol} / \mathrm{L}$ (Figure 2B), and propofol $200 \mu \mathrm{mol} / \mathrm{L}$ (Figure 2C) were obtained. Low concentrations of propofol ranging from 10 to $25 \mu \mathrm{mol} / \mathrm{L}$ significantly reduced FM1-43 fluorescence, corresponding to exocytosis of previously labeled vesicular clusters $\left({ }^{*} P<0.01\right.$ compared to photobleaching) (Figure 2D). On the other hand, high doses of propofol (50-200 $\mu \mathrm{mol} / \mathrm{L})$ had no effect on FM143 destaining from motor nerve terminals (Figure 2D), suggesting a dose-dependent effect of the anesthetic agent.
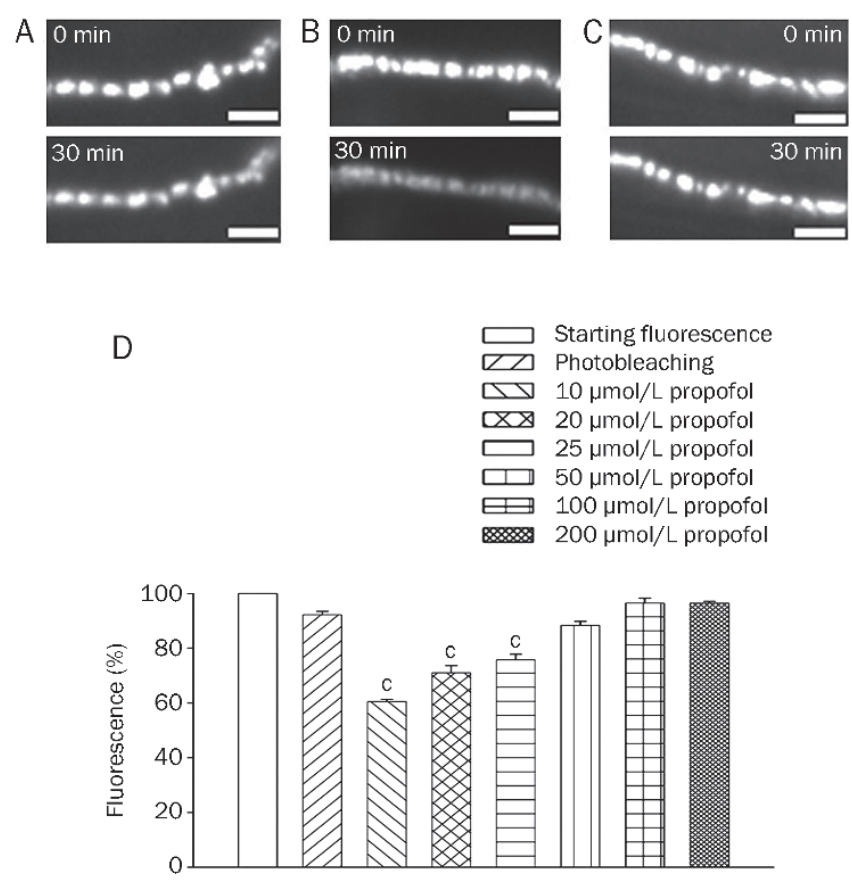

Figure 2. Dose-response curve of exocytosis induced by propofol. (A) Representative image of fluorescence loss due to photobleaching during illumination for $30 \mathrm{~min}$. Upper panel: before illumination. Lower panel: after 30 min of illumination. (B) Representative image of fluorescence loss before (upper panel) and after (lower panel) $30 \mathrm{~min}$ in the presence of propofol $10 \mu \mathrm{mol} / \mathrm{L}$. (C) Representative image of fluorescence loss before (upper panel) and after (lower panel) $30 \mathrm{~min}$ in the presence of propofol $200 \mu \mathrm{mol} / \mathrm{L}$. (D) Quantification of exocytosis evoked by different concentrations of propofol. The results are mean \pm SEM of 131 fluorescent spots from 15 nerve terminals of 8 animals. ${ }^{c} P<0.01$ compared to the second bar (photobleaching). Scale Bar=10 $\mu \mathrm{m}$.

The next set of experiments was performed to identify the mechanism(s) by which low doses of propofol induced exocytosis of synaptic vesicles. Pre-incubation of nerve terminals with TTX $(1.0 \mu \mathrm{mol} / \mathrm{L})$, a voltage-gated $\mathrm{Na}^{+}$-channel blocker, did not affect the vesicle exocytosis evoked by propofol (data not shown). By contrast, the effect of low doses of propofol 
on spontaneous exocytosis monitored by FM1-43 destaining was $\mathrm{Ca}^{2+}$-dependent (Figure 3A). Indeed, we observed a statistically significant inhibition of exocytosis evoked by low doses of propofol in the presence of the external $\mathrm{Ca}^{2+}$ chelator EGTA $(2.0 \mathrm{mmol} / \mathrm{L})$ or in the presence of omega-toxin GVIA ( $5 \mu \mathrm{mol} / \mathrm{L}$ ), that blocks N-type calcium channels (Figure $3 \mathrm{~A}$ ). The FM1-43 destaining in the presence of GVIA was not significantly different from that due to photobleaching $(P>0.05)$. In addition, we observed that the effect of low doses of propofol on synaptic vesicles exocytosis was independent on intracellular $\mathrm{Ca}^{2+}$ stores (Figure 3B). Our data suggest that FM1-43 destaining induced by propofol $(10 \mu \mathrm{mol} / \mathrm{L})$ was $\mathrm{Ca}^{2+}$ dependent and $\mathrm{Na}^{+}$-independent.

\section{Effects of high concentrations of propofol on exocytosis evoked} by depolarizing stimuli

It has been shown that propofol at concentrations around 100 $\mu \mathrm{mol} / \mathrm{L}$ inhibits skeletal muscle evoked contractions ${ }^{[15,16]}$. We therefore tested in our system if this concentration of propofol could alter with 4AP-evoked FM1-43 destaining, which is dependent on extracellular $\mathrm{Na}^{+}$. The incubation of nerve terminals with $4 \mathrm{AP}(1.0 \mathrm{mmol} / \mathrm{L})$ during $30 \mathrm{~min}$ induced a significant FM1-43 destaining (Figure 4A). The destaining evoked by $4 \mathrm{AP}$ was reduced by TTX $(P<0.01$ compared to $4 \mathrm{AP}$ alone). Pre-incubation of FM1-43 stained nerve terminals with propofol $(100 \mu \mathrm{mol} / \mathrm{L})$ also reduced the $4 \mathrm{AP}$-evoked exocytosis (Figure $4 \mathrm{~A} ; P<0.01$ compared to $4 \mathrm{AP}$ alone). Moreover, the simultaneous pre-incubation with propofol $(100 \mu \mathrm{mol} / \mathrm{L})$ and TTX $(1.0 \mu \mathrm{mol} / \mathrm{L})$ produced a significant inhibition of $4 \mathrm{AP}$ evoked FM1-43 destaining without any additive effect (Figure $4 \mathrm{~A})$, suggesting that propofol reduces the $4 \mathrm{AP}$-induced vesicle exocytosis by blocking $\mathrm{Na}^{+}$channels sensitive to TTX.

We next tested the effect of high doses of propofol on $\mathrm{Na}^{+}-$ independent exocytosis evoked by modified Ringer containing $60 \mathrm{mmol} / \mathrm{L} \mathrm{KCl}$. Nerve terminals were stained with FM1-43
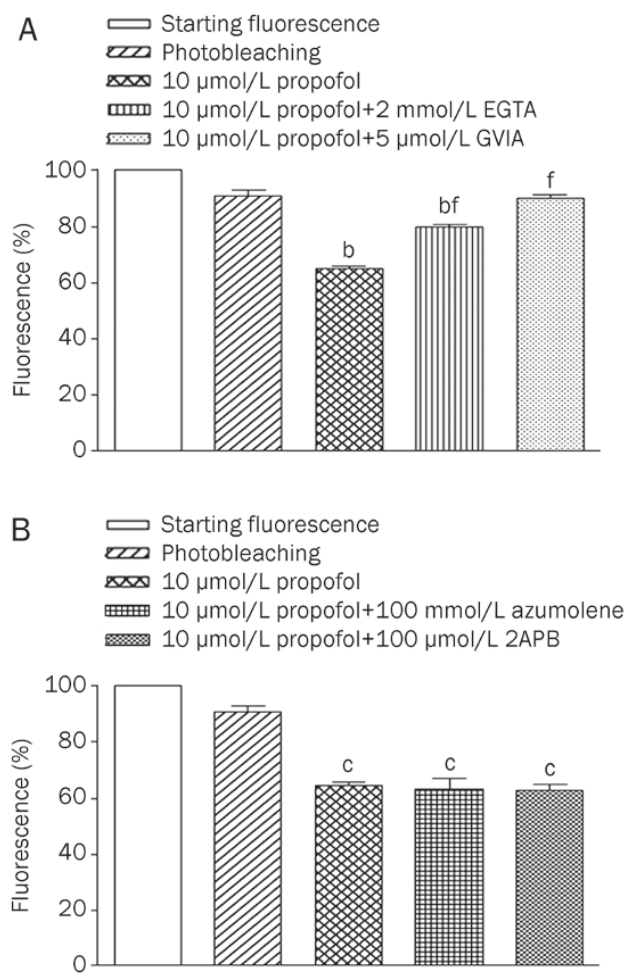

Figure 3. Low doses of propofol evoke synaptic vesicles exocytosis that is dependent on external calcium. (A) FM1-43 destaining evoked by photobleaching (second bar), propofol $(10 \mu \mathrm{mol} / \mathrm{L})$ (third bar), propofol $(10 \mu \mathrm{mol} / \mathrm{L})+$ EGTA $(2 \mathrm{mmol} / \mathrm{L})$ (fourth bar), propofol $(10 \mu \mathrm{mol} / \mathrm{L})+\mathrm{GVIA}(5$ $\mu \mathrm{mol} / \mathrm{L}$ ) (fifth bar). Note that even though EGTA was apparently slightly less effective than GVIA, both agents inhibited the propofol-evoked destaining. The results are mean \pm SEM of 192 fluorescent spots from 20 nerve terminals of 10 animals. ${ }^{\mathrm{b}} P<0.05$ compared to the second bar (photobleaching). ${ }^{\mathrm{f}} P<0.01$ compared to propofol $(10 \mu \mathrm{mol} / \mathrm{L})$. (B) FM1-43 destaining evoked by photobleaching (second bar), propofol (10 $\mu \mathrm{mol} / \mathrm{L})$ (third bar), propofol $(10 \mu \mathrm{mol} / \mathrm{L})+$ azumolene $(100 \mu \mathrm{mol} / \mathrm{L})$ (fourth bar), propofol $(10 \mu \mathrm{mol} / \mathrm{L})+2 \mathrm{APB}(100 \mu \mathrm{mol} / \mathrm{L})$ (fifth bar). The results are mean \pm SEM of 237 fluorescent spots from 18 nerve terminals of 9 animals. ${ }^{\mathrm{C}} P<0.01$ compared to the second bar (photobleaching).
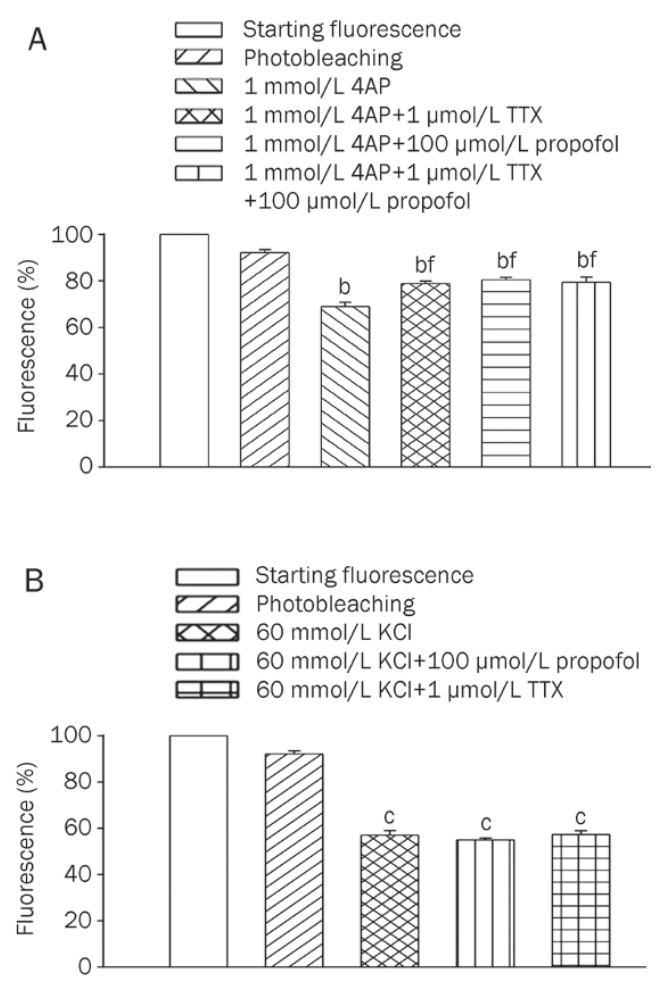

Figure 4. High doses of propofol inhibit synaptic vesicles exocytosis by a $\mathrm{Na}^{+}$-dependent manner. (A) Graphic comparing FM1-43 destaining evoked by photobleaching (second bar), 4AP (1 mmol/L, third bar), 4AP (1 mmol/L)+TTX (1 $\mu \mathrm{mol} / \mathrm{L})$ (fourth bar), 4AP (1 mmol/L)+propofol (100 $\mu \mathrm{mol} / \mathrm{L})$ (fifth bar) and 4AP (1 mmol/L)+propofol $(100 \mu \mathrm{mol} / \mathrm{L})+\mathrm{TTX}$ $(1 \mu \mathrm{mol} / \mathrm{L})$ (sixth bar). The results are mean \pm SEM of 114 fluorescent spots from 10 nerve terminals of 5 animals. ${ }^{b} P<0.05$ compared to the second bar (photobleaching). ${ }^{f} P<0.01$ compared to $4 A P(1 \mathrm{mmol} / \mathrm{L})$. (B) Quantification of exocytosis evoked by photobleaching (second bar), $\mathrm{KCl}(60$ $\mathrm{mmol} / \mathrm{L})$ (third bar); $\mathrm{KCl}(60 \mathrm{mmol} / \mathrm{L})+$ propofol (100 $\mu \mathrm{mol} / \mathrm{L})$ (fourth bar); $\mathrm{KCl}(60 \mathrm{mmol} / \mathrm{L})+\mathrm{TTX}(1 \mu \mathrm{mol} / \mathrm{L})$ (fifth bar). The results are mean $\pm \mathrm{SEM}$ of 120 fluorescent spots from 10 nerve terminals of 5 animals. ${ }^{c} P<0.01$ compared to the second bar (photobleaching). 
and we observed a significant reduction on fluorescence after incubation with $\mathrm{KCl}$ for 30 min (Figure 4B). Pre-incubation of terminals with TTX had no effect on $\mathrm{KCl}$-evoked reduction in fluorescence, confirming the data that depolarization induced by high concentration of $\mathrm{K}^{+}$is independent of extracellular $\mathrm{Na}^{+{ }^{29]}}$ (Figure 4B). In addition, pre-incubation with high doses of propofol did not inhibit $\mathrm{KCl}$-evoked $\mathrm{Na}^{+}$-independent exocytosis (Figure 4B). Taken together, these results suggest that high doses of propofol inhibit synaptic vesicles exocytosis on the neuromuscular junction by a $\mathrm{Na}^{+}$-dependent manner.

\section{Discussion}

Propofol is widely used during general anesthesia, as well as for sedation in the intensive care unit. However, fatigue of the respiratory muscles, especially the diaphragm, may cause respiratory failure. Indeed, it has been demonstrated that volatile (halothane, enflurane, isoflurane, and sevoflurane) and intravenous (propofol and midazolam) anesthetics cause diaphragmatic contractile dysfunction which may probably contributes to acute respiratory failure ${ }^{[19-21,30-32]}$. Studies in vivo suggested that several mechanisms such as reduction of blood flow, failure of neuromuscular transmission, and impairment of membrane excitation and excitation-contraction (E-C) coupling may be responsible for the neuromuscular effects of propofol. However, in vivo studies preclude any specification regarding the mechanism involved on the anesthetic effect and the use of the fluorescent probe FM1-43 enabled us to assess specifically a presynaptic effect of this agent on the neuromuscular junction. Hemmings et $a l^{[30]}$ had already performed a pioneer study on cultured hippocampal neurons using this fluorescent dye to probe synaptic vesicles exocytosis in the presence of isoflurane and they showed that isoflurane depresses exocytosis evoked by multiple presynaptic targets.

In the present work, we examined the effect of propofol on spontaneous and evoked synaptic vesicle exocytosis at the neuromuscular junction, an experimental model that provides a direct way to investigate neurotransmitter release in an isolated synapse. We found that propofol, at low concentrations ranging from 10 to $25 \mu \mathrm{mol} / \mathrm{L}$, induced synaptic vesicles exocytosis monitored by FM1-43 destaining on a $\mathrm{Ca}^{2+}$-dependent and $\mathrm{Na}^{+}$-independent manner. By contrast, high concentrations of propofol ranging from 50 to $200 \mu \mathrm{mol} / \mathrm{L}$ were ineffective to induce synaptic vesicle exocytosis.

It is well known that exocytosis depends on external $\mathrm{Ca}^{2+[23]}$ and we observed that in the absence of this ion, there was a significant reduction on FM1-43 destaining evoked by low doses of propofol, suggesting that synaptic vesicles exocytosis evoked by propofol is $\mathrm{Ca}^{2+}$-dependent. In addition, we investigated which calcium channel subtype could be the target of low doses of propofol at the frog neuromuscular junction and we observed an inhibition of propofol evoked exocytosis in the presence of the $N$-type inhibitor omega-conotoxin GVIA. Because the FM1-43 destaining evoked by propofol in the presence of GVIA was similar to that due to photobleaching $(P>0.05)$, we suggest that propofol might act on $\mathrm{N}$-type calcium channels promoting calcium influx that is coupled to synaptic vesicles exocytosis. Different from our data, previous works performed in CNS synapses have shown a predominant inhibition of calcium channels by propofol ${ }^{[5-7]}$. However, none of them have shown evidences that $N$-type calcium channels could be a target for propofol action. This discrepancy might be due to the fact that these studies were performed in brain slices that maintain intact neuronal circuitry whereas in the present work we were looking at nerve terminals without connection with motor neuron cell bodies. Therefore, we cannot rule out the possibility that propofol may exert an inhibitory effect on calcium channels located at motor neurons' cell bodies that are located at the spinal cord. Because we are looking at events that take place exclusively at the synaptic nerve terminal, such inhibition would not be detected in our experimental model. Nonetheless, our data provide direct evidences that low doses of propofol might act through $N$-type calcium channel that are directly coupled to synaptic vesicle exocytosis at motor nerve terminals. Moreover, we showed that propofol and $\mathrm{KCl}$-evoked exocytosis were not affected by TTX suggesting that both conditions did not increase the synaptic vesicle exocytosis by interfering with $\mathrm{Na}^{+}$channels. Therefore, propofol and $\mathrm{KCl}$ can induce exocytosis in a $\mathrm{Ca}^{2+}$-dependent and $\mathrm{Na}^{+}$-independent fashion suggesting that this anesthetic may act directly on $\mathrm{Ca}^{2+}$ entry through $\mathrm{N}$-type voltage-gated $\mathrm{Ca}^{2+}$ channels.

In agreement with our data, it has been observed that low concentrations of propofol increased the amplitude of the indirectly-elicited twitch and tetanic contractions in chick biventer cervices skeletal muscle, indicating that, in low concentrations, this anesthetic may stimulate skeletal muscle ${ }^{[14]}$.

Previous work showed that propofol, at concentrations of 42 and $112 \mu \mathrm{mol} / \mathrm{L}$, inhibited contraction of isolated rat diaphragm by decreasing ACh release on neuromuscular junction $^{[16]}$. These authors also observed that this agent inhibited muscle contraction evoked by electrical field stimulation, suggesting that propofol, at this concentration range, may act by inhibiting $\mathrm{Ca}^{2+}$ entry through presynaptic voltage-gated $\mathrm{Ca}^{2+}$ channels. In the present work high doses of propofol inhibited $\mathrm{Na}^{+}$-dependent exocytosis evoked by $4 \mathrm{AP}$ but did not have any significant effect on $\mathrm{Na}^{+}$-independent exocytosis evoked by $\mathrm{KCl}$. The decrease on vesicle exocytosis induced by $4 \mathrm{AP}$ in the presence of high doses of propofol is in correspondence with data showing a decreasing on the contractility of fatigued canine diaphragm with propofol in a dose-related fashion ${ }^{[21]}$. Previous studies in rat brain synaptosomes showed that propofol inhibits $\mathrm{Ca}^{2+}$-dependent glutamate release evoked by veratridine and 4-AP with greater potency than $\mathrm{Na}^{+}$channelindependent release evoked by $\mathrm{KCl}^{[33-36]}$. In addition, it has been observed that high concentrations of propofol selectively inhibited 4AP-evoked but not $\mathrm{KCl}$-evoked $\left[{ }^{3} \mathrm{H}\right]$ norepinephrine release $^{[37]}$. Considering that high doses of propofol inhibited 4AP-evoked synaptic vesicles exocytosis in a similar manner to TTX and did not interfere with $\mathrm{KCl}$-evoked exocytosis, we could suggest that the effect of propofol on neuromuscular junction is thus caused primarily by inhibition of action potential-evoked synaptic vesicle exocytosis at a step upstream of 
$\mathrm{Ca}^{2+}$ entry through voltage-gated $\mathrm{Ca}^{2+}$ channels, possibly as a result of $\mathrm{Na}^{+}$channel blockade. In addition, there are evidences in the literature suggesting that high doses of propofol might have a direct effect on $\mathrm{Na}^{+}$channels ${ }^{[10,12,13]}$. Finally, experiments in dogs show that administration of propofol decreases diaphragm contractility in a dose-dependent manner and that high dose of this anesthetic produces a progressive decrease in contractility ${ }^{[18]}$. Based on the data presented here, we could speculate that such diaphragmatic dysfunction might be due to a presynaptic effect of high doses of propofol. In addition, propofol and midazolam seems to cause diaphragm dysfunction through mechanisms other than E-C coupling failure ${ }^{[23]}$. However, the clinical importance of the present data requires further investigations and we are unable to extrapolate our in vitro findings to the clinical practice.

It is difficult to correlate the concentrations of anesthetics used in vitro experiments with those used during clinical anesthesia and it has been shown that the doses of intravenous anesthetics required in the case of experimental animals are 10-100 times higher than those used for humans ${ }^{[38]}$. Plasma concentrations of propofol during anesthesia in humans are estimated to range between 70 and $106 \mu \mathrm{mol} / \mathrm{L}^{[35,39-41]}$. Because of the high protein binding (98\%), the half-maximal effect free concentration of propofol is around $2.0 \mu \mathrm{mol} / \mathrm{L}^{[35,42,43]}$. It has been suggested that brain concentrations of propofol are about eight-fold higher than plasma free concentrations ${ }^{[44]}$ but there is no estimative of the concentrations on neuromuscular junction. Moreover, the propofol concentration producing loss of righting reflex in Rana pipiens tadpoles ranged between 1 and $10 \mu \mathrm{mol} / \mathrm{L}^{[45]}$ an end point that usually occurs at a lower concentration than surgical anesthesia. Finally, it has been argued that clinically relevant concentrations are difficult to estimate ${ }^{[1-4]}$ and it is important to mention that clinically relevant concentrations of anesthetic are important to examine the integrated responses in the intact animal but their relevance to in vitro studies should be taken with care due to our lack of understanding of how to integrate in vitro systems into the anesthesia model ${ }^{[46]}$.

In conclusion, we showed that propofol has a dual effect on the exocytosis of cholinergic synaptic vesicles from the neuromuscular transmission and the present results may contribute to understanding some of the clinical effects observed with this agent on neuromuscular function.

\section{Acknowledgements}

This work was supported by grants from CNPq, FAPEMIG and CAPES. We thank Dr Hugh C HEMMINGS Jr for valuable comments on this manuscript.

\section{Author contribution}

Luciana Ferreira LEITE and Matheus de Castro FONSECA performed research and analysed data; Renato Santiago GOMEZ designed research and wrote the paper; Marcus Vinicius GOMEZ wrote the paper; Cristina GUATIMOSIM design research and analysed data.

\section{References}

1 Franks NP, Lieb WR. Molecular and cellular mechanisms of general anaesthesia. Nature 1994; 367: 607-14.

2 Yamakura T, Bertaccini E, Trudell JR, Harris RA. Anesthetics and ion channels: molecular models and sites of action. Annu Rev Pharmacol Toxicol 2001; 41: 23-51.

3 Hemmings HC Jr, Akabas MH, Goldstein PA, Trudell JR, Orser BA, Harrison NL. Emerging molecular mechanisms of general anesthetic action. Trends Pharmacol Sci 2005; 26: 503-10.

4 Franks NP. Molecular targets underlying general anaesthesia. $\mathrm{Br} J$ Pharmacol 2006; 147: S72-81.

5 Inoue Y, Shibuya I, Kabashima N, Noguchi J, Harayama N, Ueta Y, et al. The mechanism of inhibitory actions of propofol on rat supraoptic neurons. Anesthesiology. 1999; 91: 167-78.

6 Shirasaka T, Yoshimura Y, Qiu DL, Takasaki M. The effects of propofol on hypothalamic paraventricular nucleus neurons in the rat. Anesth Analg 2004; 98: 1017-23.

7 Martella G, De Persis C, Bonsi P, Natoli S, Cuomo D, Bernardi G, et al. Inhibition of persistent sodium current fraction and voltage-gated L-type calcium current by propofol in cortical neurons: implications for its antiepileptic activity. Epilepsia 2005; 46: 624-35.

8 Ratnakumari L, Hemmings HC Jr. Effects of propofol on sodium channel-dependent sodium influx and glutamate release in rat cerebrocortical synaptosomes. Anesthesiology 1997; 86: 428-39.

9 Lingamaneni R, Birch ML Hemmings HC Jr. Widespread inhibition of sodium channel-dependent glutamate release from isolated nerve terminals by isoflurane and propofol. Anesthesiology 2001; 95 : 1460-6.

10 Frenkel C, Urban BW. Human brain sodium channels as one of the molecular target sites for the new intravenous anaesthetic propofol (2,6-diisopropylphenol). Eur J Pharmacol 1991; 208: 75-9.

11 Frenkel C, Duch DS, Urban BW. Effects of iv anaesthetics on human brain sodium channels. Br J Anaesth 1993; 71: 15-24.

12 Lingamaneni R, Hemmings HC Jr. Differential interaction of anaesthetics and antiepileptic drugs with neuronal $\mathrm{Na}^{+}$channels, $\mathrm{Ca}^{2+}$ channels, and GABA(A) receptors. Br J Anaesth 2003; 90: 199-211.

13 Martella G, De Persis C, Bonsi P, Natoli S, Cuomo D, Bernardi G, et al. Inhibition of persistent sodium current fraction and voltage-gated L-type calcium current by propofol in cortical neurons: implications for its antiepileptic activity. Epilepsia 2005; 46: 624-35.

14 Wali FA. Effects of some intravenous anaesthetics on the contractile responses produced in the chick biventer cervicis skeletal muscle. Pharmacol Res Commun 1985; 17: 361-76.

15 Lebeda MD, Wegrzynowicz ES, Wachtel RE. Propofol potentiates both pre- and postsynaptic effects of vecuronium in the rat hemidiaphragm. Br J Anaesth 1992; 68: 282-5.

16 Abdel-Zaher AO, Askar FG. The myoneural effects of propofol emulsion (Diprivan) on the nerve-muscle preparations of rats. Pharmacol Res 1997; 36: 323-32.

17 Robertson EN, Fragen RJ, Booij LH, van Egmond J, Crul JF. Some effects of diisopropylphenol (ICl35868) on the pharmacodynamics of atracurium and vecuronium in anaesthetized man. $\mathrm{Br} J$ Anaesth 1983; 55: 723-8.

18 Fujii Y, Hoshi T, Takahashi S, Toyooka H. Propofol decreases diaphragmatic contractility in dogs. Anesth Analg 1999; 89: 1557-60.

19 Fujii Y, Hoshi T, Takahashi S, Toyooka H. The effect of sedative drugs on diaphragmatic contractility in dogs: propofol versus midazolam. Anesth Analg 2000; 91: 1035-7.

20 Fujii Y, Uemura A, Toyooka H. The dose-range effects of propofol on the contractility of fatigued diaphragm in dogs. Anesth Analg 2001; 
93: $1194-8$.

21 Fujii Y, Toyooka H. Midazolam versus propofol for reducing contractility of fatigued canine diaphragm. Br J Anaesth 2001; 86: 879-81.

22 Bouhemad B, Langeron O, Orliaguet G, Coriat P, Riou B. Effects of halothane and isoflurane on the contraction, relaxation and energetics of rat diaphragmatic muscle. Br J Anaesth 2002; 89: 479-85.

23 Nishina K, Mikawa K, Kodama S-I, Kagawa T, Uesugi T, Obara H. The effects of enflurane, isoflurane, and intravenous anesthetics on rat diaphragmatic function and fatigability. Anesth Analg 2003; 96: 1674-8.

24 Betz WJ, Bewick GS. Optical analysis of synaptic vesicle recycling at the frog neuromuscular junction. Science 1992; 255: 200-3.

25 Betz WJ, Mao F, Bewick GS. Activity-dependent fluorescent staining and destaining of living vertebrate motor nerve terminals. J Neurosci 1992; 12: 363-75.

26 Gaffield MA, Betz WJ. Imaging synaptic vesicle exocytosis and endocytosis with FM dyes. Nat Protoc 2006; 1: 2916-21.

27 Guatimosim C, Romano-Silva MA, Gomez MV, Prado MAM. Use of fluorescent probes to follow membrane traffic in nerve terminals. Braz J Med Biol Res 1998; 31: 1491-500.

28 Rizzoli So, Richards DA, Betz WJ. Monitoring synaptic vesicle recycling in frog motor nerve terminals with FM dyes. J Neurocytol 2003; 32: $539-49$.

29 Nicholls DG. The glutamatergic nerve terminal. Eur J Biochem 1993; 212: 613-31.

30 Hemmings HC Jr, Yan W, Westphalen RI, Ryan TA. The general anesthetic isoflurane depresses synaptic vesicle exocytosis. Mol Pharmacol 2005; 67: 1591-9.

31 Kochi T, Ide T, Isono S, Mizuguchi T, Nishino T. Different effects of halothane and enflurane on diaphragmatic contractility in vivo. Anesth Analg 1990; 70: 362-8.

32 Ide $\mathrm{T}$, Kochi T, Isono S, Mizuguchi T. Diaphragmatic activity during isoflurane anaesthesia in dogs. Acta Anaesthesiol Scand 1993; 37: 253-7.

33 Kagawa T, Maekawa N, Mikawa K, Nishina K, Yaku H, Obara H. The effect of halothane and sevoflurane on fatigue-induced changes in hamster diaphragmatic contractility. Anesth Analg 1998; 86: 392-7.

34 Südhof TC. The synaptic vesicle cycle: a cascade of protein-protein interactions. Nature 1995; 375: 645-53.
35 Ratnakumari L, Hemmings HC Jr. Effects of propofol on sodium channel-dependent sodium influx and glutamate release in rat cerebrocortical synaptosomes. Anesthesiology 1997; 86: 428-39.

36 Lingamaneni R, Birch ML, Hemmings HC Jr. Widespread inhibition of sodium channel-dependent glutamate release from isolated nerve terminals by isoflurane and propofol. Anesthesiology 2001; 95 : 1460-6.

37 Pashkov VN, Hemmings HC Jr. The effects of general anesthetics on norepinephrine release from isolated rat cortical nerve terminals. Anesth Analg 2002; 95: 1274-81.

38 Wakasugi M, Hirota K, Roth SH, Ito Y. The effects of general anesthetics on excitatory and inhibitory synaptic transmission in area CA1 of the rat hippocampus in vitro. Anesth Analg 1999; 88: 676-80.

39 Smith C, McEwan Al, Jhaveri R, Wilkinson M, Goodman D, Smith R, et al. The interaction of fentanyl on the CP50 of propofol for loss of consciousness and skin incision. Anesthesiology 1994; 81: 820-8.

40 Kazama T, Ikeda K, Morita K. The pharmacodynamic interaction between propofol and fentanyl with respect to the suppression of somatic or hemodynamic responses to skin incision, peritoneum incision, and abdominal wall retraction. Anesthesiology 1998; 89: 894-06.

41 Haeseler G, Störmer M, Bufler J, Dengler R, Hecker H, Piepenbrock S, et al. Propofol blocks human skeletal muscle sodium channels in a voltage-dependent manner. Anesth Analg 2001; 92: 1192-8.

42 Servin F, Desmonts JM, Haberer JP, Cockshott ID, Plummer GF, Farinotti R. Pharmacokinetics and protein binding of propofol in patients with cirrhosis. Anesthesiology 1988; 69: 887-91.

43 Rehberg B, Duch DS. Suppression of central nervous system sodium channels by propofol. Anesthesiology 1999; 91: 512-20.

44 Shyr MH, Tsai TH, Tan PP, Chen CF, Chan SH. Concentration and regional distribution of propofol in brain and spinal cord during propofol anesthesia in the rat. Neurosci Lett 1995; 184: 212-5.

45 Tonner PH, Poppers DM, Miller KW. The general anesthetic potency of propofol and its dependence on hydrostatic pressure. Anesthesiology 1992; 77: 926-31.

46 Eckenhoff RG, Johansson JS. On the relevance of "clinically relevant concentrations" of inhaled anesthetics in in vitro experiments. Anesthesiology 1999; 91: 856-60. 